\title{
Reference data on hand grip and lower limb strength using the Nintendo Wii balance board: a cross-sectional study of 354 subjects from 20 to 99 years of age
}

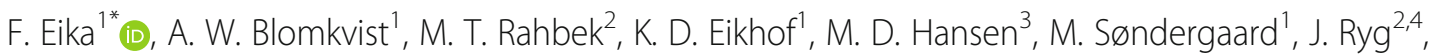

S. Andersen ${ }^{1,5}$ and M. G. Jorgensen ${ }^{1}$

\begin{abstract}
Background: Accurate assessment of isometric hand grip strength (HGS) and isometric lower limb strength $(L S)$ are often limited to specialized clinics due to high costs and need for specialized equipment and personnel. A mobile and user-friendly device would facilitate a wider use of these measures in the clinical setting. The Nintendo Wii Balance Board (WBB) is a novel and pragmatic tool that has been validated for measuring muscle strength and other clinically relevant physiological variables. However, reference data for HGS and LS are lacking. The purpose of the current study is to establish reference data for HGS and LS in individuals $\geq 20$ years of age using the WBB method, and to characterize the effects of age in these measurements.
\end{abstract}

Method: Healthy participants were recruited at various locations and their HGS and LS were tested by six assessors using the WBB. Reference data were analysed and presented in age-groups, while the age-related change in HGS and LS was tested and characterized with linear regression models.

Results: Three hundred and fifty-four participants between 20 and 99 years of age were tested. Data are presented separately according to gender and the following age categories: 20-29, 30-39, 40-49, 50-59, 60-69, 70-79, and 80+, and presented in absolute values as well as percentiles. The main findings were; (1) Significantly higher HGS and LS among males compared to females and for the dominant limb compared to the non-dominant limb, (2) a significant decline in strength with increasing age, and (3) the rate of decline increased significantly (i.e. it was non-linear) with age for HGS, but not for LS.

Conclusion: This study reported reference data with percentiles for a novel method for assessing HGS and LS. Data were consistent with previously known effects of age and gender on HGS and LS. The presented data may supplement future trials using the WBB in research or in the clinical setting.

Keywords: Nintendo Wii balance board, Isometric hand grip strength, Isometric lower limb strength, Muscle strength and aging, Normative data, Reference data, Force plate

\footnotetext{
* Correspondence: eikafredrik@gmail.com

1 Department of Geriatric and Internal Medicine, Aalborg University Hospital,

Hobrovej 18-22, 9000 Aalborg, Denmark

Full list of author information is available at the end of the article
}

(c) The Author(s). 2019 Open Access This article is distributed under the terms of the Creative Commons Attribution 4.0 International License (http://creativecommons.org/licenses/by/4.0/), which permits unrestricted use, distribution, and reproduction in any medium, provided you give appropriate credit to the original author(s) and the source, provide a link to the Creative Commons license, and indicate if changes were made. The Creative Commons Public Domain Dedication waiver (http://creativecommons.org/publicdomain/zero/1.0/) applies to the data made available in this article, unless otherwise stated. 


\section{Background}

Normal musculoskeletal function, especially adequate strength in upper and lower extremities, is important for coping with everyday activities, and is a prerequisite for participating in sports, manual labour etc. [1]. Abnormal musculoskeletal function and low muscle strength has been associated with future disability [2], increased fall risk [3-8], and mortality [9-12], leading to significant healthcare expenditures [13]. The ability to accurately assess and monitor musculoskeletal function is important during growth, aging, training, rehabilitation, scientific research, and when screening for fall risk in older adults [14]. Muscle strength can be assessed either during a dynamic concentric/eccentric or isometric contraction. The most common method for assessing strength in the clinical setting is isometric manual muscle testing (subjective scale from 0 to 5). Simplicity, swiftness, and easy application makes it a popular method in everyday clinical practice. However, its crudeness [15] makes it unreliable for strength assessment both within and between different assessors [16]. Contrary to this are hand grip- and stationary isometric/isokinetic dynamometers, which are considered the reference standards for measuring hand grip strength (HGS) and lower limb strength (LS). The hand grip dynamometers have shown high test-retest reliability and concurrent validity [17-19]. Most widely used is the Jamar dynamometer (JD), but the apparatus is primarily found in specialized clinics as it provides data for a single clinical parameter (HGS) and comes at a fairly high price of 200 to 1200 USD [20].

In contrast to HGS assessment, the stationary isometric/isokinetic dynamometer for LS assessment has never gained ground for clinical use, mainly because of the need for large scale and expensive equipment. Hand-held-dynamometry has been a feasible alternative for measuring LS owing to its light weight, versatility, and relatively low price $[21,22]$. However, the reproducibility of hand-held-dynamometry varies greatly depending on study population, operator, and muscle group tested [23]. In fact, the participant may overpower the tester [24] or the tester may overpower the participant [25]. In short, HGS and LS are useful parameters for detecting and monitoring individuals at high risk for adverse outcomes $[12,26]$ but the assessment using validated methods are usually restricted to universities and university hospitals. A promising new method for measuring HGS and LS is the use of a standard Nintendo Wii Balance Board (WBB) and customized software $[20,23,27]$. The method has a good validity when compared against the reference standards for HGS and LS [20, 23, 27]. It has also been shown to be valid for testing reaction time $[28,29]$, muscle force steadiness [30], and postural balance in younger [31] and older adults $[32,33]$. Hence, the WBB has the potential to provide accurate assessment of several physiological measures, previously unavailable in a community setting. Still, reference data on HGS and LS using this method is lacking. Therefore, the aim of this study was to (1) establish reference data for HGS and LS in healthy individuals $\geq 20$ years of age using the WBB method and (2) to describe the effects of age in these measurements.

\section{Method}

\section{Study design \& population}

This was a cross-sectional study where all measurements (physiological and anthropometric) were collected during a single test session. Participants were recruited during the spring and summer of 2016 at various locations (e.g. university campus, malls, hospital staff, and senior citizen clubs) in Denmark. People were eligible for inclusion if they were $\geq 20$ years of age and considered themselves at good health. Exclusion criteria were obvious cognitive problems (i.e. could not name present year or capital of Denmark), insufficient ability to stand unsupported for $30 \mathrm{~s}$, neuromuscular deficits (e.g. parkinson, myastenia gravis, sequela after stroke, or severe polyneuropathy), or musculoskeletal disease (e.g fracture or orthopedic surgery within the last 6 months, alloplasty in the last 2 years, muscular dystrophy, or polymyositis rheumatica). Participant characteristics included age, gender, weight, height, hand and leg dominance, smoking status, and number of prescribed drugs used daily. Finally, data was collected for the participants' physical activity at work and during leisure time, using a method similar to the Copenhagen City Heart Study [34].

\section{Equipment and software}

The WBB (Nintendo, Kyoto, Japan) is a small force plate, instrumented with four uni-axial stain gauge transducers positioned in each corner, similar to what is typically seen in professional force platforms. Data is transferred wirelessly to a personal computer via Bluetooth Human Interface Device and onto the FysioMeter software (Bronderslev, Denmark). From each of the transducers, channels of 16-bit digital data at approximately $100 \mathrm{~Hz}$ are filtered using a 4th order Butterworth filter (cut-off $20 \mathrm{~Hz}$ ).

\section{Overall experimental procedure}

Six operators measured balance, reaction time, HGS, and LS. The operators were three medical doctors (FE, $\mathrm{AWB}$, and MTR), two nurses (KDE and MS), and one physiotherapist $(\mathrm{MDH})$. Testing procedures were standardized and operators were synchronized with each other at the Department of Geriatrics, Aalborg University Hospital, Denmark prior to data collection. To minimize systematic bias, each operator collected approximately seven to nine individuals from each of the 
seven age groups $(20-29,30-39,40-49,50-59,60-69$, $70-79$, and $80+$ years).

After explaining the testing procedures, acquiring oral consent, and collecting anthropometric data, the measurements were performed in the following order: balance, reaction time, HGS, and LS.

This order was chosen as previous studies have shown that testing maximum muscle strength before postural balance could affect the balance results [35]. Coefficient of variance were calculated during HGS and LS measurements. A coefficient of variance of more than $10 \%$ in consecutive measurements initiated a re-test of the lowest value to avoid excessive variance between the measurements. If the subsequent measurement was still more than $10 \%$ off the higher value, the higher value was re-tested.

Detailed protocols for assessment of balance and reaction time are available elsewhere [28, 32], and reference data on reaction time can be found in a separate publication [29].

\section{Hand grip strength (HGS) procedure}

The participant was placed in a chair with the back straight and shoulders in their anatomical position. The WBB was held vertically, resting on the thighs, with the back of the board facing their torso at about $20 \mathrm{~cm}$ distance [20]. While squeezing the corner of the WBB with either left or right hand (Fig. 1), the participant and operator viewed the force-time curve in real time on the computer screen. After 2-3 submaximal recordings for familiarization, maximal isometric HGS was assessed beginning with the left hand and followed by the opposite hand in an alternating fashion for a total of two recordings per side. The participant was encouraged to squeeze as long and hard as possible until a plateau on the

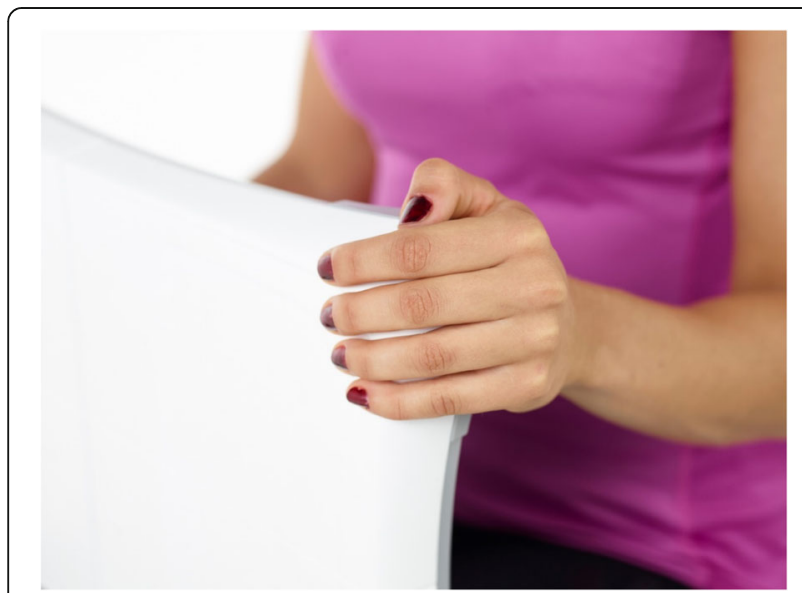

Fig. 1 Participant squeezing one of the force transducers of the Nintendo Wii Balance Board during isometric hand grip strength testing force-time curve was reached. Then the operator told the participant to stop squeezing. If such a plateau was not reached, the participant was instructed to stop when he or she was unable to further increase the force recording on the force-time curve. The output used for further analyses for each side was the average of the two maximal isometric HGS recordings.

\section{Lower limb strength (LS) procedure}

The WBB was mounted to a custom-made aluminium frame and attached via belts to a harness around the participants hips prior to testing (Fig. 2). With the participant placed in a standard chair (seat height approximately $45 \mathrm{~cm}$ ) with the back straight and shoulders in their anatomical position. The equipment was adjusted so that the knee was flexed at 60 degrees during loading. Grabbing onto the sides of the chair, one leg was placed in the middle of the WBB, before trials of 2-3 submaximal loads and two maximal loads were performed. Submaximal loads were performed for habituation, to reduce variance and to ensure correct knee angle while pressing. Four tests were performed (two for each leg), in alternating fashion, starting with the left leg. A force-time curve provided real time visual feedback to the participant during testing, as this has shown to influence output [36]. For the two maximal recordings, the participant was encouraged to squeeze as long and hard as possible until a plateau was reached on the force-time curve. As with HGS, if such a plateau was not reached, the participant was instructed to stop when he or she

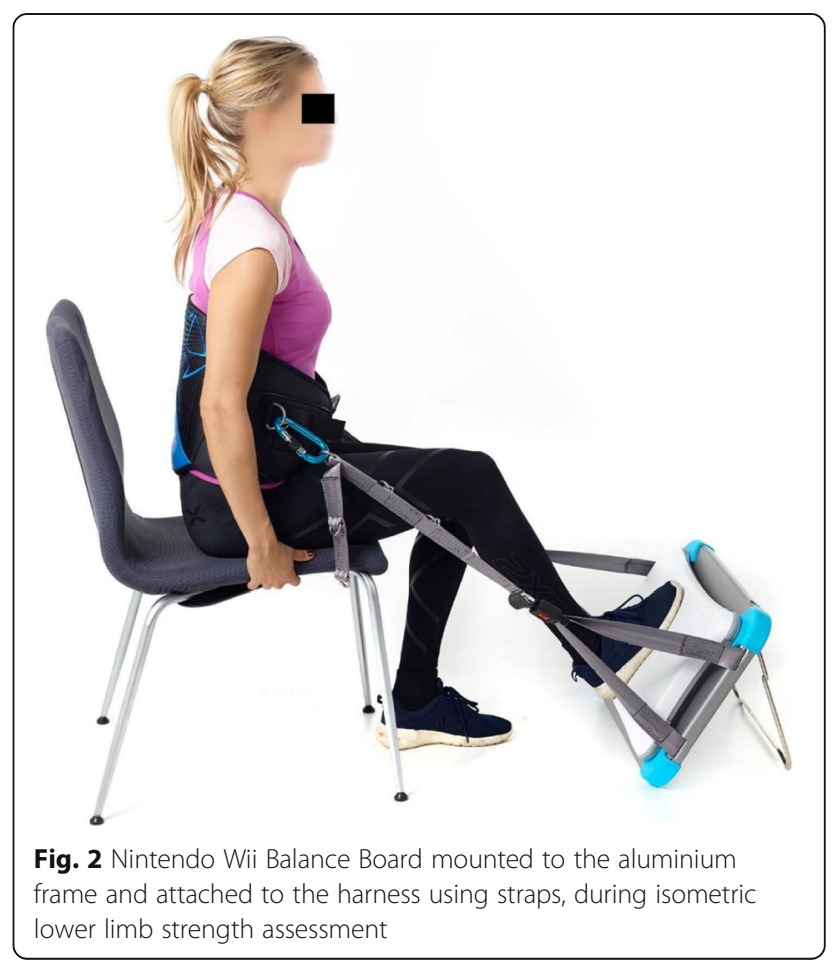


was unable to further increase the force recording on the force-time curve. The output used for further analyses for each side was the average of the two maximal isometric LS recordings.

\section{Statistical analysis}

All data were plotted in a Microsoft Excel spreadsheet and statistical analyses were performed using the Statistical Program for the Social Sciences (SPSS, version 24). All results are given in mean \pm standard deviation (SD) for normally distributed data (Shapiro-Wilk) and median with interquartile range for non-normal distributions. From the FysioMeter ${ }^{\bullet}$ software, four variables of muscle strength were extracted for each participant: HGS for dominant and non-dominant side (HGS-D, HGS-ND, respectively) and LS for dominant and non-dominant side (LS-D, LS-ND, respectively). Individuals were divided according to age groups $(20-29,30-39,40-49$, $50-59,60-69,70-79$, and $80+$ years) and gender (male, female). Using outlier labelling rule [37], outliers were identified and subsequently winsorized, except for extreme values, where measurement errors was suspected and hence, removed. For each gender and age-group, the $10,25,75$, and 90 percentiles for the four strength variables were extracted. One-sample t-test and independent $\mathrm{t}$-test was used to test for difference between the mean values for each side (dominant and non-dominant) and gender, respectively. Non-normal distributed data were tested with non-parametric tests, i.e. Mann-Whitney U test and Wilcoxon Signed-Rank test.

To investigate the age-related changes in HGS and LS, four linear regression models were calculated using the mean values for hand and feet for each gender. Assumptions of linearity and homoscedasticity were assessed with the standardized residuals plotted against predicted values, while the assumption of normal distributed errors and autocorrelations were assessed with the histogram of residuals and Durbin-Watson test (accepted value between 1.5 and 2.5), respectively [38]. Violations of linearity or homoscedasticity was corrected by transformations. The presence of non-linear relationships were statistically tested with hierarchical multiple regression using a quadratic model (i.e. adding the age squared as an independent variable to the linear regression models).

\section{Ethics}

Participants gave oral consent and the study was approved by the ethics committee of the North Jutland Region, Denmark.

\section{Results}

A total of 354 men and women, between 20 and 99 years of age, were tested. Participant characteristics are shown in Table 1. Absolute values $(\mathrm{kg})$ and percentiles $(10,25$, 75 , and $90 \%$ ) of HGS and LS for each group are shown in Tables 2 and 3, respectively. Out of 1416 observations, nine outliers were detected, of which eight were winsorized [37] and one was omitted.

As shown numerically (Table 2) and graphically (Figs. 3 and 4), both HGS and LS decreased with increased age in both genders. The linear regression (Table 4) showed a significant inverse relationship between age and strength. Age accounted for an average of 42 and $45 \%$ of the variation in HGS and LS, respectively. For HGS, the quadratic models gave a significant $\mathrm{R}^{2}$ change of $9.8 \%(\mathrm{~F}$ change $=28.4, p<0.001$ ) and $6.8 \%$ (F change 27.6, $p<$ 0.001 ) for males and females, respectively. For LS, the quadratic models gave a statistically non-significant $R^{2}$ change of $1.5 \%$ ( $\mathrm{F}$ change $=3.9, p=0.050$ ) and $1.0 \%$ ( $\mathrm{F}$ change $=3.7, p=0.055)$, for males and females, respectively. These models are illustrated in Figs. 3 and 4 together with the raw data.

There was a statistically significant gender difference $(p<0.001)$ with males being, on average, $11.1 \mathrm{~kg}(95 \%$ CI: $9.5 ; 12.7)$ and $57.9 \mathrm{~kg}$ (95\% CI: 44.9; 70.8) stronger than females for HGS and LS, respectively. The dominant side was, on average, $1.7 \mathrm{~kg}(95 \% \mathrm{CI}: 1.4 ; 2.0)$ and $3.8 \mathrm{~kg}(95 \% \mathrm{CI}: 1.8 ; 5.8)$ stronger than the non-dominant side $(p<0.001)$ for HGS and LS, respectively.

\section{Discussion}

This study reported reference data in males and females on HGS and LS using a standard WBB and investigated its relationship with age. The main findings were: (1) Significantly higher HGS and LS among males compared to females and for the dominant limb compared to the non-dominant limb, (2) a significant decline in strength with increasing age, and (3) the rate of decline increased significantly (i.e. it was non-linear) with age for HGS, but not for LS.

\section{Hand grip strength}

Hogrel et al. reported HGS using JD and MyoGrip dynamometer in a population similar to that of this study [39]. For participants aged 20-80, the averaged HGS for males and females using the JD were 40.8 and $38.5 \mathrm{~kg}$ for the right and left side, respectively. Assuming right hand dominance, the corresponding values were 26.7 and $24.8 \mathrm{~kg}$ in our study sample, revealing a difference of $14.1(35 \%)$ and $13.7(36 \%) \mathrm{kg}$. This difference is consistent with the HGS reproducibility study, which found a systematic difference between the JD and WBB of 15.4 and $11.9 \mathrm{~kg}$ for the right and left side, respectively [20]. This systematic difference is also consistent with studies comparing JD and other dynamometers [39-42]. Also, supporting the external validity of the method, the mean HGS for the 30 subjects (both genders, mean age 69 
Table 1 Study-population characteristics

\begin{tabular}{|c|c|c|c|c|c|c|c|c|c|}
\hline $\begin{array}{l}\text { Age group } \\
\text { (years) }\end{array}$ & Gender \& number & Age (years) & Height $(\mathrm{cm})$ & Weight (kg) & BMI $\left(\mathrm{kg} / \mathrm{m}^{2}\right)$ & $\begin{array}{l}\text { Medicine } \\
\text { (number) }\end{array}$ & $\begin{array}{l}\text { Smoking } \\
(\mathrm{N} ; \mathrm{C}+\mathrm{P}) \%\end{array}$ & $\begin{array}{l}\text { Physical activity } \\
\text { level work }\end{array}$ & $\begin{array}{l}\text { Physical activity } \\
\text { level leisure }\end{array}$ \\
\hline \multirow[t]{2}{*}{$20-29$} & M 22 & $24.5 \pm 2.5$ & $184 \pm 4.8$ & $85 \pm 11.7$ & $23.2 \pm 3.2$ & $0[0-1]$ & $86 ; 14$ & $2 ; 1$ & $3 ; 1.25$ \\
\hline & F 36 & $25 ; 3.8^{\mathrm{a}}$ & $167 \pm 5.8$ & $62 \pm 7.5$ & $23.2 \pm 3.2$ & $0[0-1]$ & $86 ; 14$ & $2 ; 1$ & $3 ; 1$ \\
\hline \multirow[t]{2}{*}{ 30-39 } & M 15 & $33.3 \pm 2.4$ & $182 \pm 4.8$ & $85 \pm 17.8$ & $25.9 \pm 5.7$ & $0[0-0]$ & $73 ; 27$ & $2 ; 0$ & $3 ; 1$ \\
\hline & F 30 & $33.5 ; 6.3^{\mathrm{a}}$ & $167 \pm 5.9$ & $73 \pm 16.3$ & $26.0 \pm 5.7$ & $0[0-1]$ & $80 ; 20$ & $2 ; 1$ & $2.5 ; 1$ \\
\hline \multirow[t]{2}{*}{$40-49$} & M 20 & $44.7 \pm 2.9$ & $182 \pm 6.0$ & $90 \pm 15.4$ & $27.2 \pm 4.7$ & $0[0-0]$ & $55 ; 45$ & $2 ; 1$ & $3 ; 2$ \\
\hline & F 21 & $46 ; 5.0^{\mathrm{a}}$ & $170 \pm 4.5$ & $79 \pm 15.3$ & $27.2 \pm 4.7$ & $0[0-0]$ & $67 ; 33$ & 2,$5 ; 1,75$ & $3 ; 1.5$ \\
\hline \multirow[t]{2}{*}{ 50-59 } & M 16 & $54.9 \pm 3.3$ & $183 \pm 6.1$ & $87 \pm 12.4$ & $25.9 \pm 3.8$ & $0[0-1]$ & $63 ; 38$ & 2,$5 ; 1$ & $3 ; 1$ \\
\hline & F 30 & $54.4 \pm 2.9$ & $166 \pm 6.9$ & $73 \pm 12.9$ & $25.8 \pm 3.9$ & $1[0-2]$ & $53 ; 47$ & $2 ; 2$ & $2 ; 1$ \\
\hline \multirow[t]{2}{*}{$60-69$} & M 19 & $65.3 \pm 2.3$ & $180 \pm 7.0$ & $94 \pm 18.8$ & $27.5 \pm 5.7$ & $0[0-4]$ & $42 ; 58$ & $2 ; 2$ & $3 ; 1$ \\
\hline & F 35 & $66 ; 6.0^{\mathrm{a}}$ & $166 \pm 5.6$ & $73 \pm 14.2$ & $27.6 \pm 5.7$ & $1[0-2]$ & $60 ; 40$ & $3 ; 1$ & $3 ; 1$ \\
\hline \multirow[t]{2}{*}{ 70-79 } & M 32 & $73.5 \pm 2.8$ & $178 \pm 6.2$ & $86 \pm 10.9$ & $26.9 \pm 3.9$ & $1[0-3]$ & $44 ; 56$ & b & $3 ; 1$ \\
\hline & F 33 & $73.6 \pm 2.8$ & $167 \pm 5.4$ & $74 \pm 12.7$ & $26.9 \pm 3.9$ & $1[1-5]$ & $64 ; 36$ & b & $2 ; 1$ \\
\hline \multirow[t]{2}{*}{$80+$} & M 20 & $85.6 \pm 4.1$ & $175 \pm 5.1$ & $82 \pm 10.6$ & $25.8 \pm 3.5$ & $3[0-6]$ & $35 ; 65$ & b & $2 ; 2$ \\
\hline & F 25 & $85.6 \pm 4.0$ & $163 \pm 6.6$ & $67 \pm 11.6$ & $25.7 \pm 3.6$ & $3[1-5]$ & $52 ; 48$ & b & $3 ; 1.5$ \\
\hline
\end{tabular}

Anthropometric data for the different age and gender groups. Medicine refers to number of drugs used daily. Smoking is divided into never (N) and current (C) or prior $(\mathrm{P})$ and given in percentages. Physical activity at work and during leisure time is reported in medians from 1 (least active) to 4 (most active) and variance as interquartile range

a median (interquartile range)

${ }^{\mathrm{b}} \mathrm{An}$ insignificant number of participants were working (i.e. most participants where fully retired)

years) tested in the WBB reproducibility study was 21.4 $\mathrm{kg}$, while it was $21.5 \mathrm{~kg}$ for the participants between 60 and 79 years in the current study.

It was found that the dominant hand was stronger for every age group (on average $1.7 \mathrm{~kg}$ stronger) and males were generally stronger than females (on average $11.1 \mathrm{~kg}$ ). These findings are consistent with other studies using different methods [39-41, 43], although the difference between dominant and non-dominant is sometimes small and statistically non-significant [44]. Moreover, the gender difference varied with age and with smaller difference for older adults compared to midlife and young adults. One reason could be a gender difference in survival, in which a larger proportion of surviving females are strong compared

Table 2 HGS and LS (absolute values)

\begin{tabular}{|c|c|c|c|c|c|}
\hline Age group(years) & Gender \& number & HGS-D & HGS-ND & LS-D & LS-ND \\
\hline \multirow[t]{2}{*}{ 20-29 } & M 22 & $35.4 \pm 8.4$ & $33.0 \pm 7.0$ & $238.8 \pm 56.5$ & $232.5 \pm 58.1$ \\
\hline & F 36 & $21.7 \pm 3.5$ & $19.9 \pm 4.5$ & $172.8 \pm 37.5$ & $165.1 \pm 38.0$ \\
\hline \multirow[t]{2}{*}{ 30-39 } & M 15 & $37.5 \pm 6.9$ & $35.3 \pm 4.2$ & $250.7 \pm 46.6$ & $241.6 \pm 42.6$ \\
\hline & F 30 & $22.8 \pm 4.1$ & $20.8 \pm 3.6$ & $152.4 \pm 40.0$ & $149.2 \pm 37.4$ \\
\hline \multirow[t]{2}{*}{$40-49$} & M 20 & $37.4 \pm 7.3$ & $34.9 \pm 8.1$ & $206.8 \pm 65.8$ & $210.8 \pm 64.9$ \\
\hline & F 21 & $23.2 \pm 3.9$ & $21.3 \pm 3.2$ & $162.7 \pm 52.9$ & $158.5 \pm 51.5$ \\
\hline \multirow[t]{2}{*}{ 50-59 } & M 16 & $32.7 \pm 5.3$ & $31.2 \pm 7.0$ & $197.3 \pm 46.4$ & $181.9 \pm 48.7$ \\
\hline & F 30 & $20.8 \pm 4.2$ & $18.7 \pm 4.5$ & $128.9 \pm 46.7$ & $125 \pm 42$ \\
\hline \multirow[t]{2}{*}{$60-69$} & M 19 & $30.3 \pm 7.1$ & $28.1 \pm 7.3$ & $174.7 \pm 57.0$ & $168.6 \pm 50.5$ \\
\hline & F 35 & $17.9 \pm 2.9$ & $15.7 \pm 3.2$ & $104.3 \pm 31.4$ & $100.7 \pm 30.6$ \\
\hline \multirow[t]{2}{*}{ 70-79 } & M 32 & $25.0 \pm 7.3$ & $24.3 \pm 6.4$ & $148.2 \pm 48.8$ & $145.0 \pm 46.6$ \\
\hline & F 33 & $15.7 \pm 3.7$ & $14.4 \pm 3.0$ & $98.9 \pm 34.9$ & $99.1 \pm 35.7$ \\
\hline \multirow[t]{2}{*}{$80+$} & M 20 & $18.5 \pm 4.6$ & $17.6 \pm 4.2$ & $111.8 \pm 36.4$ & $108.7 \pm 40.8$ \\
\hline & F 25 & $11.9 \pm 2.0$ & $11.7 \pm 2.7$ & $53.5(33.1)^{\mathrm{a}}$ & $63.8 \pm 28.3$ \\
\hline
\end{tabular}

Results from strength assessment for male (M) and female (F) in different age groups. Hand grip strength dominant (HGS-D), hand grip strength non-dominant (HGS-ND), isometric lower limb strength dominant (LS-D) and isometric lower limb strength non-dominant (LS-ND) are given in kilograms

${ }^{a}$ Mean $59.9 \pm 27.9$

The differences between male and female gender for HGS and LS values are all statistically significant with $p<0.001$. Exceptions are; $40-49$ : LS-D ( $p=0.012$ ), LSND $(p=0.005)$. 50-59: LS-ND $(p=0.002)$ 
Table 3 HGS and LS (percentiles)

\begin{tabular}{|c|c|c|c|c|c|}
\hline Age group (years) & Gender \& number & $\begin{array}{l}\text { HGS-D } \\
10,25,75,90\end{array}$ & $\begin{array}{l}\text { HGS-ND } \\
10,25,75,90\end{array}$ & $\begin{array}{l}\text { LS-D } \\
10,25,75,90\end{array}$ & $\begin{array}{l}\text { LS-ND } \\
10,25,75,90\end{array}$ \\
\hline \multirow[t]{2}{*}{$20-29$} & M 22 & $24,31,41,47$ & $25,29,38,42$ & $151,189,285,311$ & $137,197,270,313$ \\
\hline & F 36 & $17,20,24,26$ & $14,17,23,25$ & $116,149,202,223$ & $108,134,194,218$ \\
\hline \multirow[t]{2}{*}{ 30-39 } & M 15 & $27,33,44,46$ & $28,33,37,41$ & $176,209,297,310$ & $184,206,277,303$ \\
\hline & F 30 & $19,21,26,29$ & $17,19,23,25$ & $86,122,182,198$ & $91,122,180,202$ \\
\hline \multirow[t]{2}{*}{$40-49$} & M 20 & $28,32,42,48$ & $24,28,40,42$ & $110,155,248,301$ & $132,154,265,306$ \\
\hline & F 21 & $18,20,26,29$ & $16,19,24,25$ & $91,114,204,226$ & $85,111,199,223$ \\
\hline \multirow[t]{2}{*}{$50-59$} & M 16 & $27,29,35,42$ & $23,27,35,42$ & $135,158,244,264$ & $101,153,216,239$ \\
\hline & F 30 & $16,18,24,28$ & $13,15,22,24$ & $68,89,150,193$ & $71,87,150,201$ \\
\hline \multirow[t]{2}{*}{$60-69$} & M 19 & $22,25,35,44$ & $19,22,35,39$ & $93,122,211,234$ & $95,118,214,238$ \\
\hline & F 35 & $14,16,20,22$ & $12,13,18,20$ & $62,84,120,156$ & $62,80,120,158$ \\
\hline \multirow[t]{2}{*}{ 70-79 } & M 32 & $16,19,31,36$ & $16,19,30,34$ & $94,111,175,217$ & $92,105,179,205$ \\
\hline & F 33 & $10,14,18,21$ & $10,12,16,19$ & $56,71,110,159$ & $54,70,120,166$ \\
\hline \multirow[t]{2}{*}{$80+$} & M 20 & $10,16,21,25$ & $11,15,21,23$ & $65,79,145,164$ & $56,73,145,174$ \\
\hline & F 25 & $8.7,11,13,14$ & $8.5,9.7,13,16$ & $31,40,73,110$ & $32,43,77,111$ \\
\hline
\end{tabular}

$10,25,75$ and $90 \%$ - percentiles in kilograms for male and female in the different age groups

to surviving males. Another reason could be gender differences in the contribution of physical activity to maximal strength among young and midlife adults that evens out in older adults. Among younger individuals, the relative gender difference in age group 20-40 years of age was $40 \%$. This is very similar to the reported relative gender difference in HGS for the same age group of using JD (42\%) and Dynex-dynamometer (43\%) [40].

The present study is also consistent with the expected inverse relationship between HGS and age due to decreasing neuromuscular function [39, 45, 46]. Similar to our findings, a large epidemiological meta-analysis using

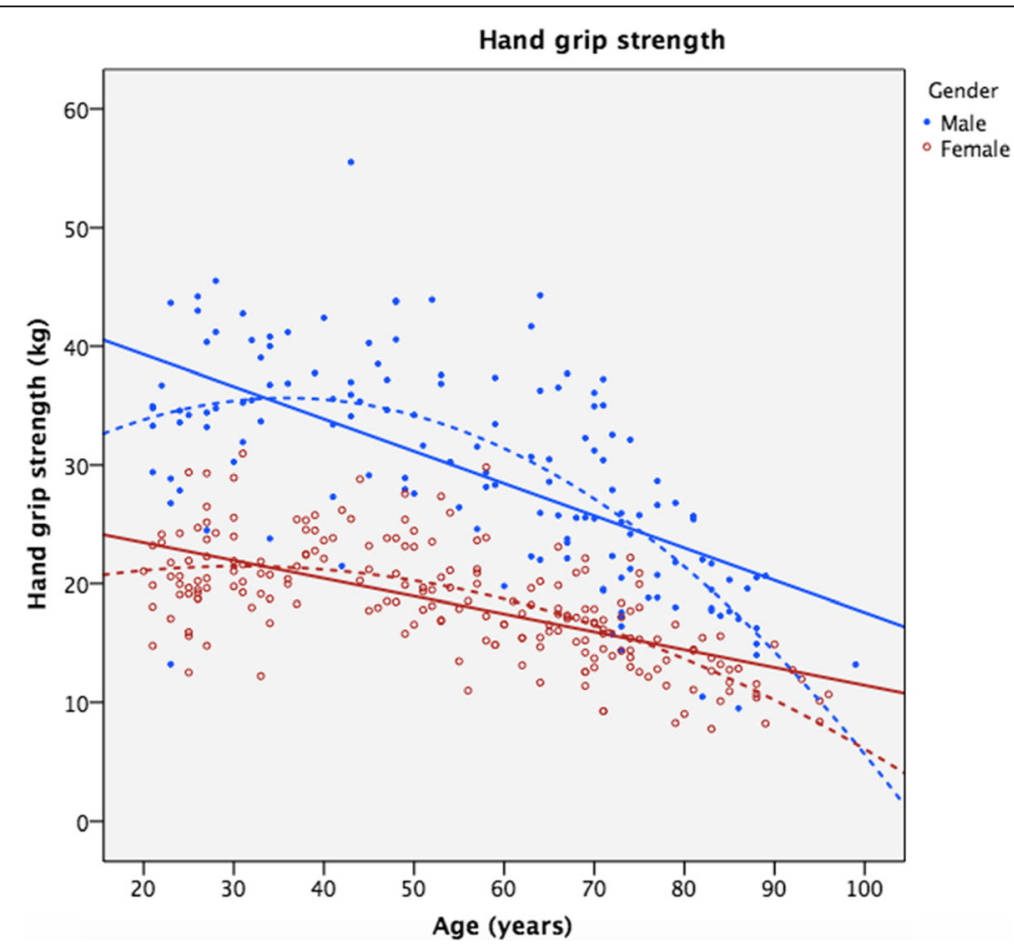

Fig. 3 Hand grip strength data in kilograms as a function of age. Solid lines represent linear regression models, while dotted lines are quadratic regression models 


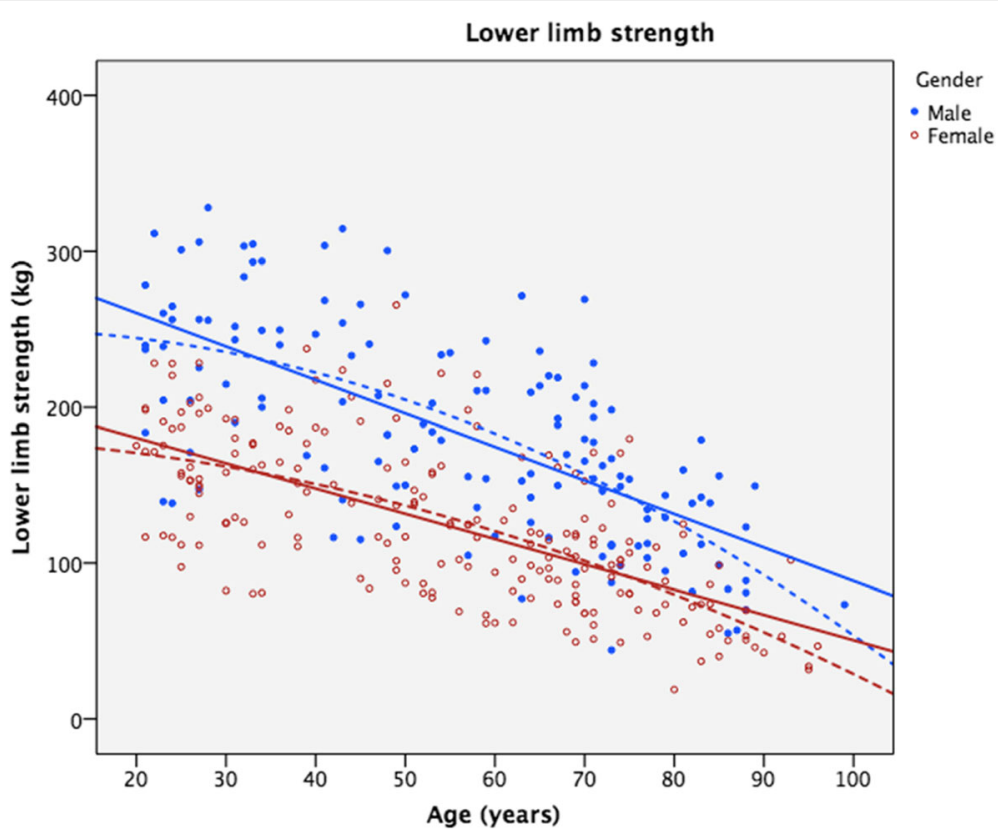

Fig. 4 Lower limb strength data in kilograms as a function of age. Solid lines represent linear regression models, while dotted lines are quadratic regression models

multiple dynamometers found an increase in HGS into adult life, peaking around 30 to 40 years of age, broad maintenance through midlife to around 60 years of age before declining [47]. Many factors may contribute to this late in life loss, such as decreased muscle protein synthesis, changes in body composition due to metabolic disorders, and reduced ability to exercise [46]. As found in other studies as well, this relationship is significantly curvilinear, i.e. the rate of decline increases with age $[43,44]$. Our data do not point to reasons for this accelerating decline, but this is a topic of interest for future follow-up.

\section{Lower limb strength}

Contrary to HGS, the absolute LS values reported in this study are not fully comparable to findings from the reproducibility study [23]. In a mixed group of 30 older adults (mean age 69), LS was on average $102 \mathrm{~kg}$ and $100 \mathrm{~kg}$ for dominant and non-dominant limb, respectively [23]. Combining the 60-69 and 70-79 age group from the current study, the averaged LS was
$131 \mathrm{~kg}$ and $128 \mathrm{~kg}$, respectively. Differences between study populations may explain some of this discrepancy. The former study included a relative higher proportion of women ( $70 \%$ vs $57 \%$ in this study) and participants had a smaller body size (on average $68 \mathrm{~kg}$ vs $74 \mathrm{~kg}$ for females, $83 \mathrm{~kg}$ vs $90 \mathrm{~kg}$ for males), suggestive of a lower muscle mass in that study. Although the ratio between strength and body mass could be used, absolute values are typically reported in the literature, probably because the relationship between body mass and strength is complicated by differences in body composition. The substantial gender difference in LS is consistent with this. Clearly, poor external validity of the method may also account for a part of the discrepancy observed. Consistent with this is the fact that the WBB method has higher reliability with HGS assessment [20, 23, 27], and therefore showed better external validity for the HGS assessment than with the LS assessment. Lastly, both the current study and the reproducibility study found

Table 4 Linear regression models for muscle strength and age

\begin{tabular}{lllll}
\hline Variable & $R$ & R squared & F-value $(p$-value $)$ & Regression coefficient \\
\hline Hand grip strength & & & & \\
$\quad$ Male & .644 & .414 & $100.5(<0.001)$ & $-0.27(95 \% \mathrm{Cl}:-0.33 ;-0.22)$ \\
$\quad$ Female & .648 & .420 & $150.4(<0.001)$ & $-0.15(95 \% \mathrm{Cl}:-0.17 ;-0.13)$ \\
Lower limb strength & & & & $-2.14(95 \% \mathrm{Cl}:-2.53 ;-1.75)$ \\
$\quad$ Male & .674 & .455 & $116.7(<0.001)$ & $-1.62(95 \% \mathrm{Cl}:-1.87 ;-1.36)$ \\
$\quad$ Female & .662 & .436 & $159.3(<0.001)$ & \\
\hline
\end{tabular}


a small, albeit statistically significant for a sufficiently large sample, difference in LS between the dominant and non-dominant sides.

Previous studies on LS most often report on isolated knee or hip movements (e.g. flexion of the knee or extension of the hip) and/or provide results in newton-meters $[22,45,48]$, which are not directly comparable to our method or measurement. Still, we may compare the influence of gender and age reported in the literature, and this is consistent with our findings. On average, males are stronger and lower limb strength decreases with age $[45,48]$. In more detail, both Danneskiold et al. [45] and Harbo et al. [48] reported a consistent linear decrease in isometric knee extension with increasing age for both males and females. However, statistical test for a non-linear relationship are missing in these reports $[45,48]$. Furthermore, age accounted for more of the variation in LS than upper limb strength (i.e. higher $R^{2}$ for LS) in their reports as well as in our regression models [45].

\section{Strengths and weaknesses with the study and method} In relative values the reference data obtained using WBB in the current study appear externally valid when compared to other larger studies on HGS and LS, particularly the effects of gender, age, and dominance on strength. In absolute terms, HGS data revealed the same systematic difference with the JD as found previously with the WBB and other dynamometers. For LS, there was a discrepancy when compared with the previous study using the WBB and very few studies have measured LS in a way that is comparable to this study. A strength of the current study is the relatively large sample tested with a rigid protocol, developed in a pilot study, to minimize systematic bias. When the protocol was in place, a $3 \mathrm{~h}$ test session was held with the six raters in order to synchronize the experimental procedures. Also, to minimize bias from a single rater on a particular age group, all raters collected data from every age group. A further strength is that the HGS and LS data were collected in the participants' own home, or in a public location, as a battery of tests with balance and reaction time testing in order to simulate a community-visit risk assessment. However, the non-random selection of participants, the different testing environment (both location and time of day), and age groups compared to the validation studies are weaknesses that may introduce bias and hamper the generalizability of the results. Still, most of these limitations provide random noise to the data and the impact was reduced by the relatively large number of participants. A smaller systematic bias can be found in the age group 30-39 and 70-79, which has a relatively high number of individuals in the lower end of the age group. However, the results from these age groups follow the overall trend for all measures and the potential bias introduced is likely to be minimal.

A technical limitation with the method is that the WBB system lacks the ability to record horizontal shear forces. This primarily renders the system applicable to static or semi static testing conditions only, which is important to consider when evaluating a patient, as static and dynamic (eccentric/concentric) muscle strength may not follow the same pattern for all ages and conditions. As noted previously, the systematic difference in HGS between WBB or HDD and the reference standard (JD) hinder direct comparison of data [20]. A similar limitation exists in LS where the method also correlates strongly with the reference standard, but gives systematically lower absolute values [23, 27]. Interestingly, for bilateral LS, the WBB method has shown a higher intraclass correlation and a lower standard error of measurement and limits of agreement compared to the reference standard [27]. Future research may further elucidate advantages and disadvantages inherent in the different methods available. However, the LS assessment sometimes required that the rater stabilized the custom steel plate during maximal pressing. Also, the knee angle may have deviated from the approximate 60 degrees flexed position during pressing, which required repositioning of the straps attached to the harness. For more specific, albeit minor, limitations on each measure, these have been reported in the prior reproducibility studies $[20,27,28,32]$. More importantly, the WBB is a widely available, inexpensive, versatile, and portable instrument, that has been validated for measuring multiple clinically relevant parameters. In the current study, multiple raters collected data in a home setting, demonstrating the practicality of the method. On average, a whole test session took about $35 \mathrm{~min}$. It is a major strength that data on postural balance, reaction time, HGS, and LS can be collected within this short timeframe. The WBB appears to be gaining ground as a new and innovative measurement and exercise tool and the HGS and LS reference data established in this study could supplement further trials and clinical use.

\section{Conclusion}

In this study, we reported reference data on a new objective and portable method for reliable HGS and LS testing in a healthy population of 354 participants in the ages between 20 and 99. The results showed decreased HGS and LS with age, lower HGS and LS in women compared to men, and a significant accelerated decline in HGS with age, which is in accordance to epidemiological studies on strength. The reference data can be used for rehabilitation purposes or future screening programs attempting to identify individuals at risk for fall accidents, frailty, and sarcopenia. 


\section{Abbreviations}

HGS: Isometric hand grip strength or hand grip strength; HGS-D: Dominant side; HGS-ND: Non-dominant side; LS: Isometric lower limb strength or lower limb strength; LS-D: Dominant side; LS-ND: Non-dominant side; WBB: Nintendo Wii Balance Board; JD: Jamar dynamometer; SD: Standard deviation

\section{Acknowledgements \\ Not applicable}

\section{Funding}

Equipment and article publication fee was paid by Aalborg Universitetssykehus, Geriatrisk afdeling

\section{Availability of data and materials}

The datasets generated and/or analysed during the current study are available in the Mendeley repository, https://data.mendeley.com/datasets/zptvcx6yrx/1.

\section{Authors' contributions}

FE and AWB contributed equally to this work: data curation, formal analysis, investigation, methodology, project administration, visualization, writing, review \& editing. MTR: investigation, writing, review and editing. KDE: investigation, writing, review and editing. $\mathrm{MDH}$ : investigation, writing, review and editing. MS: investigation, writing, review and editing. JR: supervision, validation, writing, review and editing. SA: conceptualization, funding acquisition, methodology, resources, supervision, writing, review and editing. MGJ: conceptualization, methodology, project administration, resources, software, supervision, writing, review and editing. All authors read and approved the final manuscript.

\section{Ethics approval and consent to participate}

The ethics committee of the North Jutland Region, Denmark, did not provide a full ethical evaluation due to the ethically benign nature of our work (method development study) and hence did not issue an ethics idnumber. Even though the ethics committee did not need to evaluate the study protocol, all participants were required to provide oral consent to participate in the study. In other words, participant registration was synonymous with documented consent. Lastly, none of the authors had access to any personal or potentially identifying participant information.

\section{Consent for publication}

Not applicable

\section{Competing interests}

One author (MGJ) is the developer of FysioMeter (the software used). MGJ did apply for a patent on FysioMeter approximately 3 years ago, however, since then this patent has expired. To search and check for patent, please see https://www.dkpto.dk/. This does not alter our adherence to BMC policies on sharing data and materials. Also, we would like to state that MGJ has not been involved in the data collection or statistical analyses. Finally, all other authors declare that they have no conflict of interest.

\section{Publisher's Note}

Springer Nature remains neutral with regard to jurisdictional claims in published maps and institutional affiliations.

\section{Author details}

'Department of Geriatric and Internal Medicine, Aalborg University Hospital, Hobrovej 18-22, 9000 Aalborg, Denmark. ²Department of Geriatric Medicine, Odense University Hospital, Odense, Denmark. ${ }^{3}$ Department of Health Science and Technology, Aalborg University, Aalborg, Denmark. ${ }^{4}$ Institute of Clinical Research, University of Southern Denmark, Odense, Denmark. ${ }^{5}$ Department of Clinical Medicine, Aalborg University, Aalborg, Denmark.

Received: 19 September 2018 Accepted: 4 January 2019

Published online: 12 January 2019

\section{References}

1. Hasegawa R, Islam MM, Lee SC, Koizumi D, Rogers ME, Takeshima N. Threshold of lower body muscular strength necessary to perform ADL independently in community-dwelling older adults. Clin Rehabil. 2008; 22(10-11):902-10
2. Rantanen T, Guralnik JM, Foley D, Masaki K, Leveille S, Curb JD, White L. Midlife hand grip strength as a predictor of old age disability. JAMA. 1999; 281(6):558-60.

3. Benjuya N, Melzer I, Kaplanski J. Aging-induced shifts from a reliance on sensory input to muscle cocontraction during balanced standing. J Gerontol A Biol Sci Med Sci. 2004;59(2):166-71.

4. Lord SR, Ward JA, Williams P, Anstey KJ. Physiological factors associated with falls in older community-dwelling women. J Am Geriatr Soc. 1994; 42(10):1110-7.

5. Boelens $\mathrm{C}$, Hekman EEG, Verkerke GJ. Risk factors for falls of older citizens. Technol Health Care. 2013;21(5):521-33.

6. Deandrea S, Bravi F, Turati F, Lucenteforte E, La Vecchia C, Negri E. Risk factors for falls in older people in nursing homes and hospitals. A systematic review and meta-analysis. Arch Gerontol Geriatr. 2013;56(3):407-15.

7. Ganz DA, Bao Y, Shekelle PG, Rubenstein LZ. Will my patient fall? JAMA 2007;297(1):77-86

8. Ambrose AF, Paul G, Hausdorff JM. Risk factors for falls among older adults: a review of the literature. Maturitas. 2013;75(1):51-61.

9. Newman AB, Kupelian V, Visser M, Simonsick EM, Goodpaster BH, Kritchevsky SB, Tylavsky FA, Rubin SM, Harris TB. Strength, but not muscle mass, is associated with mortality in the health, aging and body composition study cohort. J Gerontol A Biol Sci Med Sci. 2006; 61(1):72-7.

10. Rantanen T, Volpato S, Ferrucci L, Heikkinen E, Fried LP, Guralnik JM Handgrip strength and cause-specific and total mortality in older disabled women: exploring the mechanism. J Am Geriatr Soc. 2003; 51(5):636-41.

11. Norman K, Stobäus N, Gonzalez MC, Schulzke J-D, M. Pirlich, and Symreng. Hand grip strength: outcome predictor and marker of nutritional status. Clin Nutr. 2011:30(2):135-42.

12. García-Hermoso A, Cavero-Redondo I, Ramírez-Vélez R, Ruiz J, Ortega FB, Lee D-C, Martínez-Vizcaíno V. Muscular strength as a predictor of allcause mortality in apparently healthy population: a systematic review and meta-analysis of data from approximately 2 million men and women. Arch Phys Med Rehabil. 2018;99:2100-2113.e5.

13. Close JCT, Lord SR, Antonova EJ, Martin M, Lensberg B, Taylor M, Hallen J, Kelly A. Older people presenting to the emergency department after a fall: a population with substantial recurrent healthcare use. Emerg Med J. 2012; 29(9):742-7.

14. Carpenter CR, Avidan MS, Wildes T, Stark S, Fowler SA, Lo AX. Predicting geriatric falls following an episode of emergency department care: a systematic review. Acad Emerg Med. 2014;21(10):1069-82.

15. Bohannon RW. Manual muscle testing: does it meet the standards of an adequate screening test? Clin Rehabil. 2005;19(6):662-7.

16. Toemen A, Dalton S, Sandford F. The intra- and inter-rater reliability of manual muscle testing and a hand-held dynamometer for measuring wrist strength in symptomatic and asymptomatic subjects. Hand Ther 2011;16(3):67-74.

17. Innes E. Handgrip strength testing: a review of the literature. Aust Occup Ther J. 1999;46(3):120-40

18. Abizanda P, Navarro JL, García-Tomás MI, López-Jiménez E. Validity and usefulness of hand-held dynamometry for measuring muscle strength in community-dwelling older persons. Arch Gerontol Geriatr. 2012; 54(1):21-7.

19. Roberts HC, Denison HJ, Martin HJ, Patel HP, Syddall H, Cooper C, Sayer AA A review of the measurement of grip strength in clinical and epidemiological studies: towards a standardised approach. Age Ageing. 2011:40(4):423-9.

20. Blomkvist AW, Andersen S, de Bruin ED, Jorgensen MG. Isometric hand grip strength measured by the Nintendo Wii balance board - a reliable new method. BMC Musculoskelet Disord. 2016;17:56.

21. Stark T, Walker B, Phillips JK, Fejer R, Beck R. Hand-held dynamometry correlation with the gold standard isokinetic dynamometry: a systematic review. PM R. 2011:3(5):472-9.

22. Martin HJ, Yule V, Syddall HE, Dennison EM, Cooper C, Aihie Sayer A. Is hand-held dynamometry useful for the measurement of quadriceps strength in older people? A comparison with the gold standard Bodex dynamometry. Gerontology. 2006:52(3):154-9.

23. Blomkvist AW, Andersen $\mathrm{S}$, de Bruin $\mathrm{E}$, Jorgensen MG. Unilateral lower limb strength assessed using the Nintendo Wii balance board: a simple and reliable method. Aging Clin Exp Res. 2016. 
24. Kelln BM, McKeon PO, Gontkof LM, Hertel J. Hand-held dynamometry: reliability of lower extremity muscle testing in healthy, physically active,young adults. J Sport Rehabil. 2008;17(2):160-70.

25. Wikholm JB, Bohannon RW. Hand-held dynamometer measurements: tester strength makes a difference. J Orthop Sport Phys Ther. 1991; 13(4):191-8.

26. Moreland JD, Richardson JA, Goldsmith $\mathrm{CH}$, Clase CM. Muscle weakness and falls in older adults: a systematic review and meta-analysis. J Am Geriatr Soc. 2004;52(7):1121-9.

27. Gronbech Jorgensen M, Andersen S, Ryg J, Masud T. Novel use of the Nintendo Wii Board for Measuring Isometric Lower Limb Strength: a reproducible and valid method in older adults. PLoS One. 2015;10(10): e0138660.

28. Jorgensen MG, Paramanathan S, Ryg J, Masud T, Andersen S. Novel use of the Nintendo Wii board as a measure of reaction time: a study of reproducibility in older and younger adults. BMC Geriatr. 2015;15:80.

29. Blomkvist AW, Eika F, Rahbek MT, Eikhof KD, Hansen MD, Søndergaard M, Ryg J, Andersen S, Jørgensen MG. Reference data on reaction time and aging using the Nintendo Wii balance board: a cross-sectional study of 354 subjects from 20 to 99 years of age. PLoS One. 2017; 12(12):e0189598.

30. Blomkvist AW, Eika F, de Bruin ED, Andersen S, Jorgensen M. Handgrip force steadiness in young and older adults: a reproducibility study. BMC Musculoskelet Disord. 2018;19(1):96

31. Clark RA, Bryant AL, Pua Y, McCrory P, Bennell K, Hunt M. Validity and reliability of the Nintendo Wii balance board for assessment of standing balance. Gait Posture. 2010;31(3):307-10

32. Jorgensen MG, Laessoe U, Hendriksen C, Nielsen OBF, Aagaard P. Intrarater reproducibility and validity of Nintendo Wii balance testing in community-dwelling older adults. Off J ICAPA wwwJAPA-Journalcom Orig Res J Aging Phys Act. 2014;22:269-75.

33. Hubbard B, Pothier D, Hughes C, Rutka J. A portable, low-cost system for posturography: a platform for longitudinal balance telemetry. J Otolaryngol Head Neck Surg. 2012;41(Suppl 1):S31-5.

34. Schnohr P. Physical activity in leisure time: impact on mortality. Risks and benefits. Dan Med Bull. 2009;56(1):40-71.

35. Granacher U, Muehlbauer T, Gschwind YJ, Pfenninger B, Kressig RW. Assessment and training of strength and balance for fall prevention in the elderly: recommendations of an interdisciplinary expert panel. Z Gerontol Geriatr. 2014;47(6):513-26.

36. Fischer SL, Belbeck AL, Dickerson CR. The influence of providing feedback on force production and within-participant reproducibility during maximal voluntary exertions for the anterior deltoid, middle deltoid, and infraspinatus. J Electromyogr Kinesiol. 2010;20(1):68-75.

37. Hoaglin DC, Iglewicz B. Fine-tuning some resistant rules for outlier labeling. J Am Stat Assoc. 1987:82(400):1147-9.

38. Field A. Discovering Statistics Using IBM SPSS Statistics. 4th ed: SAGE Publ. Ltd; 2013.

39. Hogrel J-Y. Grip strength measured by high precision dynamometry in healthy subjects from 5 to 80 years. BMC Musculoskelet Disord. 2015;16:139.

40. Shechtman O, Gestewitz L, Kimble C. Reliability and validity of the DynEx dynamometer. J Hand Ther. 2005;18(3):339-47.

41. Massy-Westropp N, Rankin W, Ahern M, Krishnan J, Hearn TC. Measuring grip strength in normal adults: reference ranges and a comparison of electronic and hydraulic instruments. J Hand Surg Am. 2004;29(3):514-9.

42. Amaral JF, Mancini M, Novo Júnior JM. Comparison of three hand dynamometers in relation to the accuracy and precision of the measurements. Brazilian J Phys Ther. 2012;16(3):216-24.

43. Werle S, Goldhahn J, Drerup S, Simmen BR, Sprott H, Herren DB. Age- and gender-specific normative data of grip and pinch strength in a healthy adult Swiss population. J Hand Surg Eur Vol. 2009;34(1):76-84.

44. Peters MJH, van Nes SI, Vanhoutte EK, Bakkers M, van Doorn PA, Merkies ISJ, Faber CG, PeriNomS study group. Revised normative values for grip strength with the Jamar dynamometer. J Peripher Nerv Syst. 2011;16(1):47-50.

45. Danneskiold-Samsøe B, Bartels EM, Bülow PM, Lund H, Stockmarr A, Holm CC, Wätjen I, Appleyard M, Bliddal H. Isokinetic and isometric muscle strength in a healthy population with special reference to age and gender. Acta Physiol. 2009;197(s673):1-68.

46. Nair KS. Aging muscle. Am J Clin Nutr. 2005;81(5):953-63.
47. Dodds RM, Syddall HE, Cooper R, Benzeval M, Deary IJ, Dennison EM, Der G, Gale CR, Inskip HM, Jagger C, Kirkwood TB, Lawlor DA, Robinson SM, Starr JM, Steptoe A, Tilling K, Kuh D, Cooper C, Sayer AA. Grip strength across the life course: normative data from twelve British studies. PLoS One. 2014;9(12):e113637.

48. Harbo T, Brincks J, Andersen H. Maximal isokinetic and isometric muscle strength of major muscle groups related to age, body mass, height, and sex in 178 healthy subjects. Eur J Appl Physiol. 2012;112(1):267-75.
Ready to submit your research? Choose BMC and benefit from:

- fast, convenient online submission

- thorough peer review by experienced researchers in your field

- rapid publication on acceptance

- support for research data, including large and complex data types

- gold Open Access which fosters wider collaboration and increased citations

- maximum visibility for your research: over $100 \mathrm{M}$ website views per year

At $\mathrm{BMC}$, research is always in progress.

Learn more biomedcentral.com/submissions 